\title{
Üretken Enerji Ölçeği'nin Geçerlik ve Güvenirlik Çalışması (Validity and Reliability Study of Productive Energy Scale)
}

\section{Mustafa BEKMEZCi iD a Kenan ORÇANLI iD b Hasan BOZTOPRAK (iD c}

a Toros Üniversitesi, İktisadi İdari ve Sosyal Bilimler Fakültesi, İşletme Bölümü, Mersin, Türkiye. mustafa.bekmezci@toros.edu.tr

b Toros Üniversitesi, İktisadi İdari ve Sosyal Bilimler Fakültesi, İşletme Bölümü, Mersin, Türkiye. kenan.orcanli@toros.edu.tr

c Beykent Üniversitesi, İktisadi ve İdari Bilimler Fakültesi, İşletme Bölümü, İstanbul, Türkiye. hasanboztoprak@beykent.edu.tr

\begin{tabular}{|c|c|}
\hline MAKALE BİLGİİ & ÖZET \\
\hline Anahtar Kelimeler: & Amaç - Yapılan çalışmanın amacı; Cole, Bruch ve Vogel (2012) tarafından geliştirilen ve halen \\
\hline Üretken Enerji & günümüzde de kullanılabileceği düşünülen Üretken Enerji Ölçeği'ni (Productive Energy Scale) \\
\hline Öröïtsel Fnerii & Türkçe'ye uyarlamak ve ulusal yazına kazandırmaktır. \\
\hline Ölçek, Geçerlik & Yöntem - Çalışma dört aşamadan oluşan bir süreç içerisinde gerçekleştirilmiştir. İlk aşamada, \\
\hline & Üretken Enerji Ölçeği'nin kavramsal ve kuramsal arka planı tartışılmıştır. İkinci aşamada, ölçeğin \\
\hline Güvenirlik & $\begin{array}{l}\text { Türkçe'ye çevirisi yapılmıştır. Bu aşamada Brislin (1970) tarafından önerilen çeviri ve geri çeviri } \\
\text { yöntemi kullanılmıştır. Üçüncü ve dördüncü aşamalarda ise ölçeğin geçerlik ve güvenirlik }\end{array}$ \\
\hline $\begin{array}{l}\text { Gönderilme Tarihi } 22 \text { Haziran } \\
2020\end{array}$ & $\begin{array}{l}\text { analizleri yapılmıştır. Ölçeğin kapsam ve mantık geçerliği için uzman görüşüne başvurulmuş, yapı } \\
\text { geçerliği ve güvenirlik analizlerinde ise ölçeğin Ankara ilinde yerleşik olan ve döküm } \\
\text { endüstrisinde faaliyet gösteren ticari bir işletmede görevli } 176 \text { yönetici ve çalışana uygulanması }\end{array}$ \\
\hline $\begin{array}{l}\text { Revizyon Tarihi } 12 \text { Ağustos } \\
2020\end{array}$ & $\begin{array}{l}\text { sonucunda elde edilen veriler kullanılmıştır. Analizler SmartPLS paket programı ve } R \\
\text { programlama dili kullanılarak gerçekleştirilmiştir. }\end{array}$ \\
\hline Kabul Tarihi 12 Eylül 2020 & $\begin{array}{l}\text { Bulgular - Çalışmanın neticesinde; ölçeğin orijinalinde olduğu gibi üç boyutlu yapısını koruduğu } \\
\text { ve güvenirliğinin oldukça yüksek olduğu tespit edilmiştir. Bu kapsamda Üretken Enerji Ölçeği'nin } \\
\text { Türkiye'de sosyal bilimlerde yapılacak araştırmalarda kullanılabileceği değerlendirilmiştir. }\end{array}$ \\
\hline $\begin{array}{l}\text { Makale Kategorisi: } \\
\text { Araştırma Makalesi }\end{array}$ & $\begin{array}{l}\text { Tartışma - Yapılan çalışmanın örgütsel davranış yazınına, araştırmacılara ve yöneticilere katkı } \\
\text { sağlayacağı öngörülmektedir. }\end{array}$ \\
\hline
\end{tabular}

\begin{tabular}{|c|c|}
\hline ARTICLE INFO & ABSTRACT \\
\hline Keywords: & $\begin{array}{l}\text { Purpose - The aim of present study is to adapt the Productive Energy Scale developed by Cole, } \\
\text { Bruch and Vogel (2012) to Turkish and to bring the scale into Turkish literature. }\end{array}$ \\
\hline $\begin{array}{l}\text { Organizational Energy } \\
\text { Scale, Validity }\end{array}$ & $\begin{array}{l}\text { Design/methodology/approach - The study was carried out in four stages. In the first stage of the } \\
\text { study, theoretical information about Productive Energy Scale was given. In the second stage of the }\end{array}$ \\
\hline Reliability & $\begin{array}{l}\text { study, the Turkish translation of the scale was made. At this stage, the translation and back } \\
\text { translation method proposed by Brislin (1970) was used. In the third and fourth stages, the validity } \\
\text { and reliability study of the scale was performed. For the content and logic validity of the scale, }\end{array}$ \\
\hline Received 22 June 2020 & \\
\hline Revised 12 August 2020 & were used in the analysis of structure validity and reliability. Analyzes were performed using \\
\hline Accepted 12 September 2020 & SmartPLS software and R programming language. \\
\hline Article Classification: & $\begin{array}{l}\text { Findings - As a result of the study; it was determined that the scale has a three-dimensional } \\
\text { structure as in the original and its reliability is quite high. In this context, Productive Energy Scale } \\
\text { can be used in research to be done before each work in the social sciences in Turkey. }\end{array}$ \\
\hline Research Article & $\begin{array}{l}\text { Discussion - It is evaluated that the study will contribute to the organizational behavior literature, } \\
\text { researchers and managers. }\end{array}$ \\
\hline
\end{tabular}




\section{GİRIŞ}

Örgütler gerek iç dinamiklerinden gerekse çevresel etmenlerden kaynaklanan değişimlere ayak uydurabilmek için organik örgüt yapısı oluşturmalı (Burns ve Stalker, 2011) ve dinamik örgütsel yetenekler geliştirmelidir. $\mathrm{Bu}$ yetenekler, yöneticilere yeni stratejiler geliştirmek için kaynak tabanını değiştirme konusunda örgütsel ve stratejik hareket kazandırmaktadır (Eisenhardt ve Martin, 2000: 1107). Dinamik yeteneklerin geliştirilmesi ve kullanılması noktasında insan kaynağının (Singh ve Rao, 2016) ve esnekliğin (Eisenhardt, Furr ve Bingham, 2010) önemi yazında dillendirilmektedir. Nitekim örgütün başarısı, örgüt çatısı altındaki kişilerin, bireysel beklenti ve hedeflerinin ötesinde bütüncül bir anlayışla ortak bir çaba sarf etmelerine ve paylaşılan bir uzgörü etrafında ortak amaçları özümsemelerine bağlıdır. Kişilerin uzgörüyü benimsemeleri ise uzgörünün çalışanları ne ölçüde heyecanlandırdığı, dinamikleştirdiği ve esinlendirdiği ile ilgili bir husustur. Bu noktada örgütlerin sadece bir örgütsel yapı inşa etmeleri, özgörev ve uzgörü ifadeleri tanımlamaları ya da çeşitli hedefler ortaya koymaları örgütsel başarı için başlı başına yeterli olmamakta, bu uygulama ve süreçleri tamamlayacak örgütsel enerji oluşturmaları da önem arz etmektedir. Nitekim örgütsel yapılar temelde durağan olup bu yapıları örgütsel hedefler çerçevesinde dinamik hale getirmek için enerji kaynağı gerekmektedir (Miner, 1980: 273).

Yüksek enerjiye sahip işletmeler, daha üretken olmalarını sağlayan bir yapıya sahip olup, sürekli tetikte olmaları dolayısıyla daha iyi ve hızlı bilgi işleme ve kaynak tahsisi yapabilmektedir. Düşük enerjiye sahip işletmeler ise yüksek enerjiye sahip işletmelerin göğüs gerdiği sürpriz ve risklerden kaçınma eğilimindedir (Bruch ve Ghoshal, 2003: 47). Örgütsel enerji miktarı, işletmelerin öncelikli hedeflerine ulaşmak için duygusal, bilişsel ve davranışsal potansiyellerinden ne ölçüde faydalandıklarını belirlemektedir (Bruch ve Kunz, 2013: 330). Doğrudan gözlemlemek ya da ölçmek zor olsa da örgütsel enerji kavramı kullanıldığında bir parça somutlaşmaktadır. Bu çerçevede örgütsel enerji; pozitif enerji (örneğin, coşku, sevinç ve memnuniyet) ya da negatif enerji (korku, hayal kırıklığı ve üzüntü) olarak nitelenebilmektedir (Bruch ve Ghoshal, 2003: 45-46). Bruch ve Kunz (2013), örgütsel enerjinin ölçümü ile ilgili aşağıdaki yorumu yapmıştır:

\section{“...Örgütsel enerji kolektif bir güçtür. Örgütsel enerji, hem en üst (kurumsal) seviyede hem de bölüm ya da takım seviyesinde ölçülebilmektedir. Bununla birlikte, örgütsel enerjinin sadece bir örgüt ya da bölümdeki bireylerinin harcadığı enerjinin bir toplamı olmadığı aksine bu bireylerin potansiyelleri arasındaki sinerjiye dayalı ilişkiden ortaya çıktığı unutulmamalıdır..." (Brunch ve Kunz, 2013: 331).}

Yazındaki bu görüşler, örgütsel enerjinin ölçümüne ve akademik alandaki kuramsal ve kavramsal gelişimine katkı sunmaktadır. Nitekim bu gelişimi destekleyici olarak yazında örgütsel enerjinin operasyonel hale getirilmesine ilişkin çeşitli araçlar geliştirilmiştir (Cole, Bruch ve Vogel, 2012; Bruch ve Vogel, 2011; Kunze ve Bruch, 2010; Atwater ve Carmeli, 2009; Bruch, Walter ve Voelpel, 2006; Cole, Bruch ve Vogel, 2005; Shirom, 2003; Dhawan, Roy ve Kumar, 2002; Tosey ve Smith, 1999). Ancak yazında önerilen bu ölçekler örgütsel enerji kavramının farklı boyutlarına ve seviyelerine hitap etmektedir. Yazında geliştirilen bu ölçeklerden güncel ve ulaşılabilir olması, örgütlerin bütününe ya da alt birimlerine uygulanabilmesi dolayısıyla Cole, Bruch ve Vogel (2012) tarafından geliştirilmiş ölçeğin önemli olduğu ve Türkçe yazına kazandırılması gerektiği düşünülmektedir. Cole, Bruch ve Vogel (2012) ölçeği, beş ülkeden (Fransa, İngiltere, İsveç, İsviçre ve $A B D$ ) elde ettikleri veriler ile test etmişlerdir. Örgütsel enerji olgusu üzerine kavramsal bir tartışma yürüten Baker (2019), örgüt düzeyindeki enerji ölçümü konusunda Cole, Bruch ve Vogel (2012) tarafından geliştirilmiş bu ölçeği işaret etmektedir. Bu bağlamda çalışmanın temel amacı örgütsel enerji konusunda bir yazın taraması sunmak ve söz konusu ölçeğin Türkçe uyarlamasını gerçekleştirmektir. Bu yönüyle çalışmanın, olgu ve ölçüm aracının ulusal yazında yer bulmasına katkı yapması beklenmektedir.

\section{2. ÖRGÜTSEL ENERJí}

Enerji olgusu, örgütsel yaşamın büyük bölümünde yaygındır (Cross vd., 2003: 51). Örgüt bağlamında ortaya çıkan örgütsel enerji kavramı ise bir örgüt ya da işbilimi bünyesindeki yönetici ve çalışanların ortak olarak sahip oldukları beşerî gücü ifade etmekte ve bireylerin sahip oldukları nitelikleri örgütsel boyuta taşımaktadır (Bruch ve Vogel, 2011: 6). Bruch ve Kunz (2013: 330)'a göre örgütsel enerji, işletmelerin faaliyetlerini yürüttükleri ve işlerini harekete geçirdikleri bir güç olarak işletmenin duygusal, bilişsel ve fiziksel unsurları arasındaki etkileşim olarak değerlendirilmektedir (Bruch ve Ghoshal, 2003: 45). Örgütsel enerji, salt bir fiziksel ya da zihinsel güç olmayıp çalışanların motivasyonunu, takım çalışması potansiyelini 
ve yenilikçi yönünü artıran ve işletmelere rekabet avantajı sağlayan anlaşılması oldukça zor olan bir özelliktir (Schiuma, Mason ve Kennerly, 2007: 69).

Örgütsel enerji kavramı ile ilişkili olarak yazında öne çıkan bir kavram ise üretken enerjidir. Kavram, Bruch ve Vogel (2011: 10) tarafından yüksek derecede pozitif enerji olarak ifade edilmekte ve yüksek etkinlik düzeyi, hız, canlılık ve üretkenlikle birlikte yüksek düzeyde duygusal katılım ve zihinsel uyanıklık olarak açıklanmaktadır. Daha kapsamlı bir tanım sunan Cole, Bruch ve Vogel (2012) ise "birlik içerisinde örgüt hedefleri için çabalayan bireyler arasındaki olumlu etki, bilişsel uyarılma ve etkin davranışların ortak deneyim ve ifadesi" olarak tanımlamış ve bireylerin duygusal, bilişsel ve davranışsal potansiyeli harekete geçirildiğinde ortaya çıtı̆̆ını ifade etmişlerdir. Üretken enerji; bilgi üretimi ve değişimi ile ilgili olup özerklik derecesi ve karar alma sürecine katılım gibi örgütsel faktörlerden etkilenebileceğinden, örgütler için önemli sonuçlar üretebilmektedir (Alexiou, Khanagha ve Schippers, 2019).

Şekil 1. Dörtlü Örgütsel Enerji Matrisi

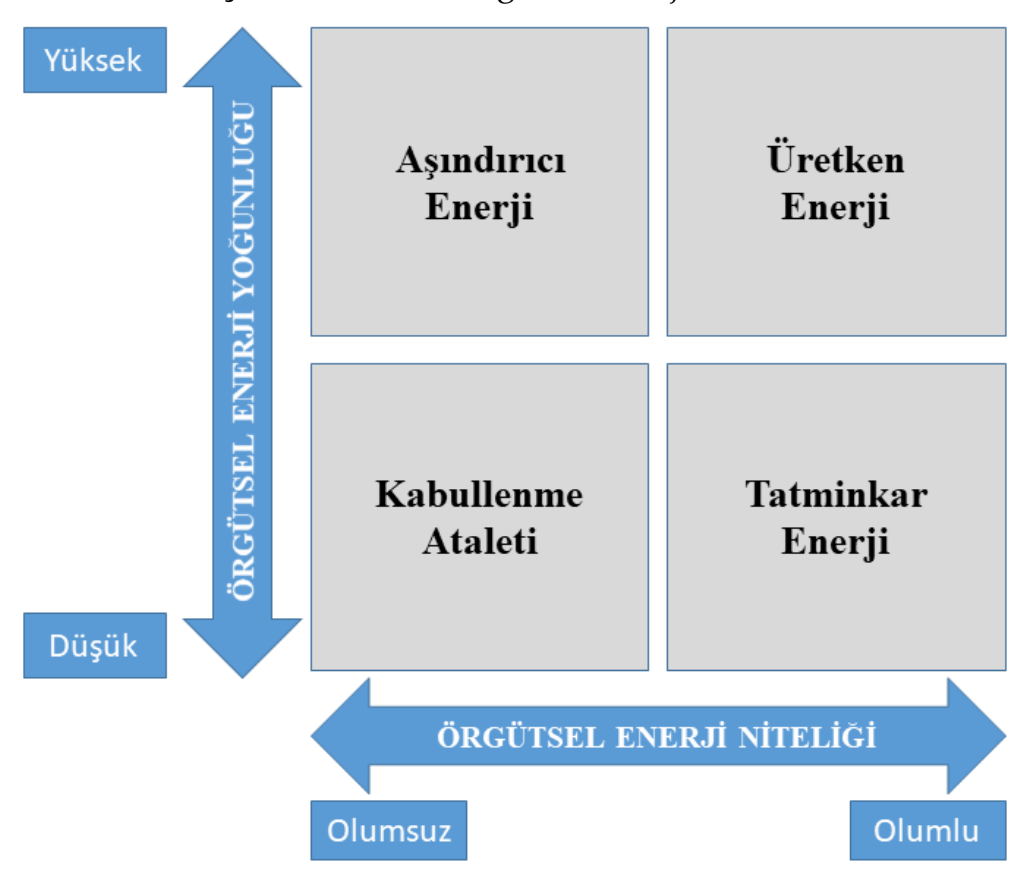

Kaynak: H. Bruch ve B. Vogel, (2011). Fully charged: How great leaders boost their organization's energy and ignite high performance. Cambridge, MA: Harvard Business School Press, 9.

Schudy ve Bruch (2010), duygusal, bilişsel ve davranışsal enerji olmak üzere örgütsel enerjiye dair üç boyut tanımlamıştır. Duygusal enerji; örgütsel hedef ve görevlere ilişkin kolektif nitelikteki olumlu duygu, coşku ve ilhamı tanımlamaktadır. Bilişsel enerji; iş ile ilgili faaliyet ve çözümler konusunda üretken ve proaktif düşünebilme becerisi anlamına gelmektedir. Davranışsal enerji ise örgütün ortak hedeflerine yönelik kolektif nitelikteki etkin davranışları ifade etmektedir.

Üretken enerji, yazında yer alan kolektif motivasyon, kolektif etkinlik, grup uyumu, duygusal iklim ve kolektif tükenme gibi kavramlarla benzerlik taşımasına (Alexiou, Khanagha ve Schippers, 2019) karşın kendine özgü bazı özelliklere sahiptir. Birincisi, üretken enerji ortak bir olgu olup bireysel düzeyde ortaya çıan fakat daha yüksek bir analiz seviyesinde, örneğin örgütsel düzeyde gerçekleşen paylaşılan bir özelliğe sahiptir. İkincisi üretken enerjinin; duygusal, bilişsel ve davranışsal enerjiden oluşan üç boyutlu bir yapıya sahip olmasıdır. Son özelliği ise kolektif olarak ortaya çıkan bir durum olmasıdır (Schudy ve Bruch, 2010). Örgütlerin süreklilik, rekabetçilik ve gelişimi için örgütlerdeki bireylerin sahip olduğu üretken enerjinin ortaya çıkarılması ve ölçülmesi önemli bir meseledir. Dolayısıyla bu amaç kapsamında üretken enerjinin ölçülebilmesi için bir ölçüm aracına ihtiyaç duyulmuştur. Söz konusu amacı gerçekleştirmek için yazında çeşitli ölçekler geliştirilmiştir. Bu ölçeklerden Cole, Bruch ve Vogel (2012) tarafından geliştirilen Üretken Enerji Ölçeği'nin önemli olduğu düşünülmektedir. Önerilen ölçek ile uluslararası yazında çeşitli çalışmaların yapıldığı ancak ulusal yazında üretken enerji kavramı ve ölçüm aracı ile ilgili herhangi bir çalışmanın 
yapılmadığı tespit edilmiştir. Dolayısıyla üretken enerji kavramı ile bu kavramı ölçen ölçüm aracının Türkçe yazına kazandırmak amacıyla bu çalışma yapılmıştır.

\section{YÖNTEM}

Bu bölümde; çalışmanın amacı, ölçek ve çalışma grubu ile ilgili bilgi, analiz için kullanılan programlar, çalışmanın sınırlılıkları, çalışmanın aşamaları ve ölçeğin Türkçe'ye uyarlama çalışması, çalışmada kullanılan analiz yöntemlerinin varsayımları, ölçeğin geçerliği ve güvenirliği kapsamında yapılan analizler yer almaktadır.

\subsection{Araştırmanın Amacı}

Bu çalışmanın amacl; Cole, Bruch ve Vogel (2012) tarafından geliştirilmiş Üretken Enerji Ölçeği'ni (Productive Energy Scale) Türkçe'ye uyarlamak, ölçeğin geçerlik ve güvenirlik çalışmasını yapmak ve ölçeği ulusal yazına kazandırmaktır.

\section{2. Üretken Enerji Ölçeği}

Üretken Enerji Ölçeği, üç boyutlu (duygusal, bilişsel ve davranışsal) bir yapıya sahiptir. Duygusal ve bilişsel alt boyutlarında beşer, davranışsal alt boyutunda ise dört madde olmak üzere toplam on dört maddeden oluşmaktadır. Duygusal alt boyutu, 1=Çok $a z, 2=A z, 3=N e$ Az Ne Fazla, 4=Fazla,5=Çok Fazla cevaplarından oluşan 5'li Likert, bilişsel ve davranışsal alt boyutları ise 1=Kesinlikle katılmıyorum, 2=Katılmıyorum, 3=Kararsızım, 4=Katılıyorum, 5=Kesinlikle katılıyorum cevaplarından oluşan 5'li Likert formdadır. Ölçeğin orijinal İngilizce versiyonu ve Türkçe'ye uyarlanmış şekli çalışmanın sonunda ek olarak sunulmuştur. Ölçeğe ilişkin elde edilen geçerlik ve güvenirlik sonuçları tatmin edicidir. Cole, Bruch ve Vogel (2012) tarafından uygulanan güvenirlik testi neticesinde Cronbach alfa değerleri; ölçeğin bütünü için 0.88 , duygusal boyut için 0.90 , bilişsel boyut için 0.77 ve davranışsal boyut için 0.61 olarak elde edilmiştir. Yazarların yaptıkları doğrulayıcı faktör analizi neticesinde elde ettiği uyum iyiliği değerleri ise $C F A=0.99$, $T L I=0.99, R M S E A=0.051$ şeklindedir. Ölçeği Güney Afrika'da test eden Grobler ve Grobler (2019), yaptıkları doğrulayıc faktör analizi neticesinde $G F I=0.99$, TLI=0.99, CFI=0.99, RMSEA=0.026 uyum iyiliği değerleri elde etmiştir. Alexiou, Khanagha ve Schippers (2019) da yaptıkları doğrulayıcı faktör analizi neticesinde uyum iyiliği indekslerini $G F I=0.91$, $T L I=0.95, R M S E A=0.08$ ve $C F I=0.96$ şeklinde elde etmiştir.

\section{3. Çalışmanın Araştırma Yöntemi, Anakütlesi ve Örneklemi}

Çalışmada kullanılan veriler, Temmuz-Ağustos 2019 tarihleri arasında Ankara ilinde yerleşik döküm endüstrisinde faaliyet gösteren özel bir işletmede görevli yöneticilerden ve çalışanlardan elde edilmiştir. Anket formu Google Formlarda hazırlanmış ve form linki ana kütledeki yönetici ve çalışanlara online olarak gönderilmiştir. Verilerin tek bir işletmeden toplanmasının amacı çalışmanın yazın incelemesi kısmında da açıklandığı üzere Türkçe'ye uyarlanması ile geçerlik ve güvenirlik çalışması yapılan ölçeğin herhangi bir örgütün tamamı ya da sadece bir alt bölümüne ait üretken enerjinin ölçülebilmesi için oluşturulmasından kaynaklanmaktadır. Anket uygulaması sırasında işletmede 18 yönetici ve 181 çalışan olmak üzere toplam 199 kişinin çalıştığı tespit edilmiştir. Anket linki bütün yönetici ve çalışanlara iletilmiş ve 180 kişiden dönüş alınmıştır. Çalışmada verilerin toplanması için Ankara'da seçilen bu işletme, yapılacak çalışma için yeterli gözlem sayısına ulaşabilmek için mevcut işletmeler arasında en uygunu olduğu için seçilmiştir.

Online anket formu, iki bölümden oluşmaktadır. Anketin birinci bölümünde katılımcıların demografik bilgileri ile ilgili sorular yer alırken, ikinci bölümünde Üretken Enerji Ölçeği'nin maddeleri yer almaktadır.

Anket uygulamasına verilen cevaplar incelendiğinde dört adet anket elenmiş ve analiz için elde 176 anket kalmıştır. Ankete katılan kişilerin demografik bilgileri Tablo 1'de verilmiştir. 
M. Bekmezci - K. Orçanlı - H. Boztoprak 12/3 (2020) 2655-2668

Tablo 1. Araştırma Grubu Demografik Bilgileri (n=176 kişi)

\begin{tabular}{|c|c|c|c|c|c|c|c|}
\hline \multicolumn{2}{|c|}{ Değişken } & \multirow{2}{*}{$\begin{array}{c}\mathbf{f} \\
\\
24 \\
152\end{array}$} & \multirow{2}{*}{$\begin{array}{c}\% \\
\\
17 \\
83\end{array}$} & \multicolumn{2}{|c|}{ Değişken } & \multirow[b]{2}{*}{$\begin{array}{c}\mathbf{f} \\
50 \\
61 \\
43 \\
17 \\
5\end{array}$} & \multirow[b]{2}{*}{$\begin{array}{c}\text { \% } \\
28 \\
35 \\
24 \\
10 \\
3\end{array}$} \\
\hline Cinsiyet & $\begin{array}{l}\text { Kadın } \\
\text { Erkek }\end{array}$ & & & \multirow[t]{2}{*}{$\begin{array}{c}\text { Kurumda } \\
\text { çalışma } \\
\text { süresi } \\
\left(Y_{11}\right)\end{array}$} & $\begin{array}{l}5 \text { ve altı } \\
6-15 \\
16-25 \\
26-35 \\
35 \text { ve üzeri }\end{array}$ & & \\
\hline & Toplam & 176 & 100 & & Toplam & 176 & 100 \\
\hline \multirow[t]{2}{*}{ Yaş } & $\begin{array}{l}21-30 \\
31-40 \\
41-50 \\
51-60 \\
61 \text { ve üzeri }\end{array}$ & $\begin{array}{c}25 \\
78 \\
64 \\
8 \\
1 \\
\end{array}$ & $\begin{array}{c}14 \\
44 \\
36 \\
5 \\
1 \\
\end{array}$ & \multirow[t]{2}{*}{ Statü } & $\begin{array}{l}\text { Yönetici } \\
\text { Çalışan }\end{array}$ & $\begin{array}{c}18 \\
158\end{array}$ & $\begin{array}{l}10 \\
90\end{array}$ \\
\hline & Toplam & 176 & 100 & & Toplam & 176 & 100 \\
\hline
\end{tabular}

\section{4. Çalışmada Kullanılan Programlar}

Bu çalışmada, SmartPLS paket programı ile R programlama dili kullanılmıştır. SmartPLS paket programı ile ölçeklerin açıklayıcı ve doğrulayıcı faktör analizleri ile güvenirlik analizleri, $\mathrm{R}$ programlama dili ile çalışmada kullanılan verilerin çok değişkenli normal dağılım gösterip göstermediği kontrol edilmiştir.

\section{5. Çalışmanın Sınırlılıkları}

Yapılan çalışma; Ankara ili, döküm endüstrisi, özel işletmelerde görevli çalışanların oluşturduğu araştırma grubu ve ölçeğin doğası cevapların tek bir işletmeden alınmasını gerektirdiğinden, örneğin alındığı işletme ile sinirlıdır.

\section{BULGULAR}

\subsection{Araştırmanın Aşamaları}

Yapılan araştırmada işlemler ve analizler üç aşamada gerçekleştirilmiştir. İlk aşamada ölçek Türkçe'ye çevrilmiş, ikinci aşamada ölçeğin uzmanların görüşüne dayanan kapsam ve mantıksal geçerliği (Ölçeğin Kapsam Geçerlik Oranı (KGO) ve Kapsam Geçerlik İndeksi (KGİ) değerlerinin hesaplanması) kontrol edilmiş, son aşamada da ölçeğin yapı geçerliği (faktör analizinin yapılması) ve diğer geçerlik analizleri (Yakınsama geçerliği, ayrışma geçerliği, uyum iyiliği değerlerinin hesaplanması) ile güvenirlik analizi (Cronbach alfa katsayısı) yapilmıştır.

\section{2. Ölçeğin Türkçe'ye Uyarlanması}

Üretken Enerji Ölçeği'nin Türkçe'ye uyarlanmasında ölçeğin orijinal dili olan İngilizce'den Türkçe'ye çevrilmesinde Brislin (1970) tarafından önerilen yöntem kullanılmıştır. Bu kapsamda ilk olarak ölçeğin, konusunda uzman dört akademisyen tarafından Türkçe tercümesi yapılmış, Türkçe'ye çevrilen ölçek maddeleri Türkçe dersi veren iki akademisyene gösterilmiş, bu akademisyenlerin tavsiyesi doğrultusunda en uygun ifadeler seçilmiş ve ölçek maddeleri bir bütün olarak birleştirilmiştir. Müteakiben, Türkçe olarak oluşturulan ölçek, dört doktora öğrencisine verilerek anlaşılması güç ifadelerin tespit edilmesi istenmiş ve alınan geri bildirim ile gerekli düzeltmeler yapılmıştır. Nihayet ölçeğin Türkçe ve İngilizce versiyonları, mesleği İngilizce öğretmeni olan kişilerden oluşan on bir örnekleme ayrı zamanlarda uygulanmış ve dilsel eş değerlik çalışması yapılmıştır. Son olarak ölçeğin güvenirliğini tespit etmek için, ölçeğin Türkçe versiyonu, akademisyenlerden oluşan yirmi beş kişilik bir gruba uygulanmıştır.

\section{3. Üretken Enerji Ölçeği'nin Geçerliği ve Güvenirliği Kapsamında Yapılan Çalışmalar}

Geçerlik, bir ölçeğin ölçmek istediği özelliği ölçmesi ile ilgili bir kavramdır. Eğer bir ölçek istenen özelliği doğru ve diğer özellikler ile karıştırmadan ölçüyorsa ölçeğin geçerli olduğu söylenir. Dört tip geçerlik türü bulunmaktadır. Bunlar; kapsam geçerliği, mantıksal geçerlik, ölçüt bağıntılı geçerlik ve yapı geçerliğidir. Bir 
M. Bekmezci - K. Orçanlı - H. Boztoprak 12/3 (2020) 2655-2668

test veya ölçek, ölçtüğü şeyi tutarlı ve istikrarlı bir şekilde ölçüyorsa, yani bir test veya ölçek benzer şartlarda tekrar uygulandığında benzer sonuçlar veriyorsa bu test veya ölçek güvenilirdir şeklinde yorumlanmaktadır (Alpar, 2012). Bu çalışmada Üretken Enerji Ölçeği'nin kapsam ve mantıksal geçerliği 20 kişilik uzman görüşüne göre, yapı geçerliği ile güvenirlik çalışması ise 176 kişilik örneklem grubundan alınan cevaplara göre SmartPLS paket programında kısmi en küçük kareler regresyonuna dayalı faktör analizi ile yapılmıştır.

\subsection{1. Ölçeğin Kapsam ve Mantıksal Geçerliği}

Üretken Enerji Ölçeği'nin kapsam ve mantıksal geçerliği ile ilgili olarak ölçek maddeleri 20 kişiden oluşan bir uzman gruba gösterilmiş ve bu uzmanlardan ölçek maddelerinin Türkiye'de sosyal bilimler alanında yapılacak akademik çalışmalar için uygun olup olmadığını değerlendirmesi istenmiştir. Bu kapsamda Üretken Enerji Ölçeği'nin kapsam ve mantıksal geçerliği ile ilgili olarak uzmanların görüşü Tablo 2'de verilmiştir.

Tablo 2. Üretken Enerji Ölçeği'nin Maddeleri Hakkında Uzman Görüşleri

\begin{tabular}{|c|c|c|c|}
\hline Maddeler & Gerekli & Gerekli, ancak yetersiz & Gerekli değil \\
\hline DUY1 & 20 & - & - \\
\hline DUY2 & 16 & 4 & - \\
\hline DUY3 & 16 & 4 & - \\
\hline DUY4 & 18 & 2 & - \\
\hline DUY5 & 18 & 2 & - \\
\hline BíL1 & 18 & 2 & - \\
\hline BíL2 & 20 & - & - \\
\hline BíL3 & 18 & 2 & - \\
\hline BíL4 & 18 & 2 & - \\
\hline BíL5 & 16 & 4 & - \\
\hline DAV1 & 18 & 2 & - \\
\hline DAV2 & 18 & 2 & 2 \\
\hline DAV3 & 18 & - & - \\
\hline DAV4 & 20 & & \\
\hline
\end{tabular}

Üretken Enerji Ölçeği'nin maddelerine ait uzman görüşlerine bağlı olarak elde edilen ve Tablo 2'de gösterilen sonuçlar, ölçeğin Kapsam Geçerlik Oranı (KGO) ve Kapsam Geçerlik İndeksi (KGİ) değerlerinin hesaplanmasında kullanılmıştır. KGO değerlerinin hesaplanmasında ((gerekli sayı-gerekli ancak yetersiz sayı)/uzman sayısı), değerlerin sıfır veya negatif değer alması durumunda ölçek maddesi ölçekten çıkarılır. Ayrıca bir ölçekte olması tavsiye edilen en düşük KGO değeri Tablo 3'te gösterilmiştir. Hesaplanan herhangi bir maddenin KGO değeri Tablo 3'te yer alan teorik değerden büyükse madde ölçekte kalmakta, küçükse madde ölçekten çıkarılmaktadır.

Tablo 3. En Düşük Kapsam Geçerlik Oranları

\begin{tabular}{|c|c|c|c|c|c|c|c|c|}
\hline Uzman Sayısı & $\mathbf{5}$ & $\mathbf{1 0}$ & $\mathbf{1 5}$ & $\mathbf{2 0}$ & $\mathbf{2 5}$ & $\mathbf{3 0}$ & $\mathbf{3 5}$ & $\mathbf{4 0}$ \\
\hline En Küçük KGO & 0.99 & 0.62 & 0.49 & 0.42 & 0.37 & 0.33 & 0.31 & 0.29 \\
\hline
\end{tabular}

Kaynak: Alpar, 2012: 415.

Ölçeğe ilişkin KGİ değerleri ise istatistiksel değerlendirme sonucunda havuzda kalan maddelerin KGO değerlerinin ortalaması hesaplanarak elde edilmektedir. Yapılan hesaplama neticesinde bulunan değerin 0.67'den büyük olması istenir. Eğer ölçek iki ve daha fazla boyutlu ise KGI'nin her boyut için ayrı ayrı da hesaplanması gerekmektedir (Alpar, 2012: 415). Bu kapsamda Üretken Enerji Ölçeği'nin maddelerinin hesaplanan KGO ve KGİ değerleri Tablo 4'te verilmiştir. 
M. Bekmezci - K. Orçanlı - H. Boztoprak 12/3 (2020) 2655-2668

Tablo 4. Üretken Enerji Ölçeği'nin Bütünü ile Alt Boyutlarının KGO ve KGİ Değerleri

\begin{tabular}{|c|c|c|}
\hline Maddeler & KGO & KGİ \\
\hline DUY1 & 1.00 & \multirow{5}{*}{0.76} \\
\hline DUY2 & 0.60 & \\
\hline DUY3 & 0.60 & \\
\hline DUY4 & 0.80 & \\
\hline DUY5 & 0.80 & \\
\hline BİL1 & 0.80 & \multirow{5}{*}{0.80} \\
\hline BíL2 & 1.00 & \\
\hline BíL3 & 0.80 & \\
\hline BìL4 & 0.80 & \\
\hline BİL5 & 0.60 & \\
\hline DAV1 & 0.80 & \multirow{4}{*}{0.85} \\
\hline DAV2 & 0.80 & \\
\hline DAV3 & 0.80 & \\
\hline DAV4 & 1.00 & \\
\hline
\end{tabular}

Üretken Enerji Ölçeği'nin maddeleri ile ilgili uzmanların görüşüne göre hesaplanan ve Tablo 4'te gösterilen KGO ile KGİ değerleri 0.05 anlamlılık düzeyinde yazında yer alan referans değerleri ile karşılaştırıldığında; tüm maddelerin uygun değerlere sahip olduğu görülmüş, Üretken Enerji Ölçeği'nin maddelerinden herhangi bir madde çıkartılmadan aynen kullanılabileceğine karar verilmiştir.

\subsection{2. Ölçeğin Yapı, Yakınsama, Ayrışma Geçerliği ile Uyum İyiliği Değerleri}

\subsubsection{Araştırma Yöntemi}

Bu çalışmada SmartPLS paket programında kısmi en küçük kareler regresyona dayalı faktör analizi ve bu analize bağlı olarak elde edilen yakınsama ve ayrışma geçerliği ve uyum iyiliği değerleri elde edilmiş ve gerekli yorumlar yapılmıştır.

Yazında genellikle ölçeklerin geçerlik ve güvenirlik analizlerinde SPSS ve AMOS paket programlarının kullanıldığı görülmektedir, bu çalışmada SmartPLS paket programı tercih edilmiştir. Çünkü SPSS ve AMOS paket programlarında yapılan parametrik analizlerde çeşitli varsayımların (Verilerin normal dağılması, örneklem sayısının 300'den fazla olması ve değişkenlerin doğrusal olması) sağlanması gerekir. Örneklem hacmi için her bir ölçülen değişken veya gösterge değişkenin en az 15 birime sahip olması gerekir (Bayram, 2016: 51). Dolayısıyla bu çalışma için en az 210 adet örneklem hacmine ihtiyaç bulunmaktadır. Ancak 176 kişiden veri toplanabilmiştir. Ayrıca eldeki verilerin çok değişkenli normal dağılım sağlaması gerekirken R programlama dilinde yapılan çok değişkenli normal dağılım testi (Henze-Zirkler Testi) sonucunda çalışmadaki verilerin, çeşitli dönüştürme metotları (Verilerin karesinin, kare kökünün, logaritmasının alınması gibi) uygulanmasına rağmen çok değişkenli normal dağılmadığ ${ }_{1}(p(0.002)<0.05$ ve $M V N: N O)$ tespit edilmiştir. $\mathrm{R}$ programlama dilinde yapılan Henze-Zirkler Testi sonuçları Tablo 5'te gösterilmiştir. Söz konusu test ile ilgili olarak R programlama dilinde readxl ve $M V N$ paketleri ve readxl ve $M V N$ kütüphaneleri kullanılmıştır. 
Tablo 5. Üretken Enerji Ölçeği Verilerinin Çok Değişkenli Normal Dağılımının Kontrolü

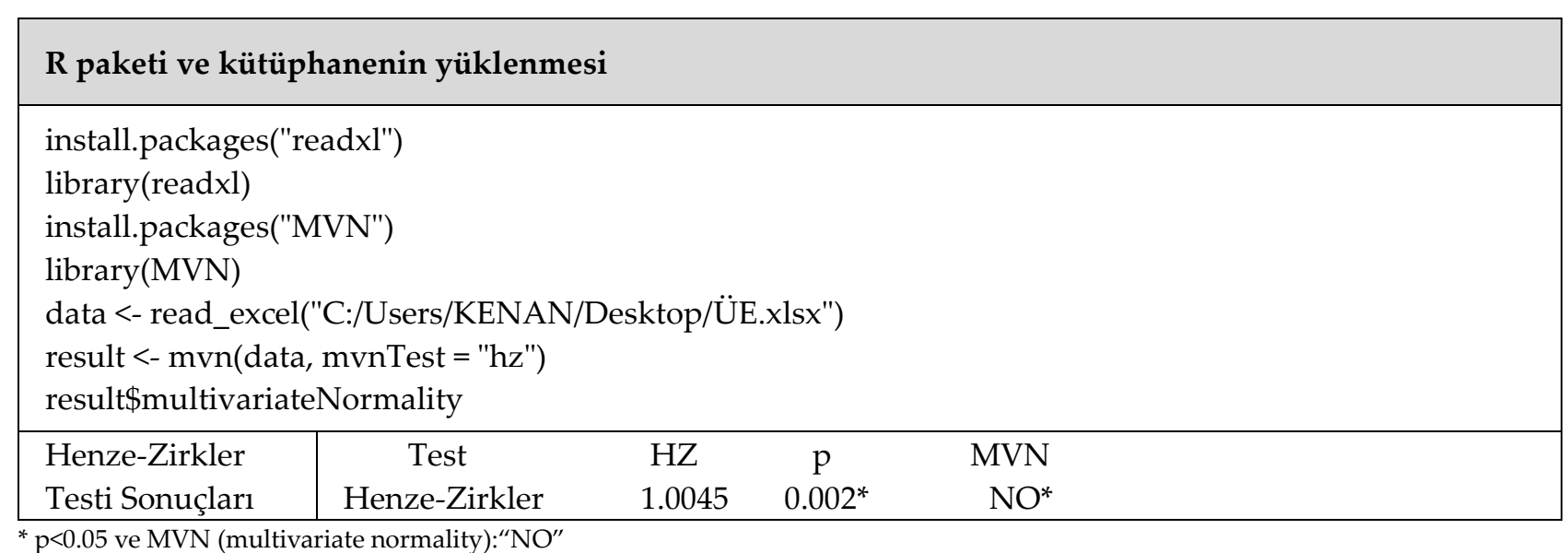

\subsubsection{2. Üretken Enerji Ölçeği'nin Yapı Geçerliği, Güvenirlik Analizi ve Uyum İyiliği İndeksleri}

Herhangi bir ölçeğin yapı geçerliğinin kontrol edilmesi kapsamında yazında genellikle açıklayıcı faktör analizi sonucunda elde edilen değerlere; güvenirliğinin kontrol edilmesi kapsamında ise Cronbach alfa ve uyum iyiliği değerlerine bakılmaktadır. Bu çalışmada ise ölçeğin yapı geçerliğinin ve güvenirliğinin kontrolü için SmartPLS paket programında faktör analizi ve buna bağlı olarak elde edilen yakınsama geçerlik değerlerine (İç Tutarlılık Katsayısı (Cronbach alfa katsayısı), Veri Tutarlılık Katsayısı, Birleşik Güvenirlik Katsayısı (CR) ve Çıkarılan Ortak Varyans (AVE)), ayrışma geçerlik değerlerine (Fornell-Larcker Kriterleri ve Heterotrait-Monotrait Oranı) ve uyum iyiliği değerlerine bakılarak kontrol edilmiştir. SmartPLS paket programında bu değerler kısmi en küçük kareler regresyonu üzerine kurulan model üzerinden hepsi aynı anda elde edilebilmektedir (Compeau ve Higgins, 1995: 128). SmartPLS paket programında sonuçlarının analiz edilmesi ve yorumlanmasında Wong (2013)'un önermiş olduğu iki aşamalı yol dikkate alınırsa, ilk aşamada, ölçüm modeli ( $D$ ış model olarak da isimlendirilir) ile işlemler yapılabilir. Ölçüm modeli, gizil değişkenler ve bunların gözlenen göstergeleri arasındaki ilişkileri belirlemektedir. İkinci aşamada, yapısal model (Íç model olarak da isimlendirilir) ile ilgili işlemler yapılır. Yapısal model, bağımsız ve bağımlı gizil değişkenler arasındaki ilişkileri belirlemektedir. Üretken Enerji Ölçeği'nin geçerliği ve güvenirliği ile ilgili işlemler yapılırken, SmartPLS paket programının birinci aşamasının ölçüm modelinden elde edilen değerler ile ikinci aşamasının yeniden örnekleme yöntemi sonucunda ölçüm modelinin anlamlılıkları sınanmıştır.

SmartPLS paket programında Üretken Enerji Ölçeği ile ilgili oluşturulan araştırma modelinin (ölçüm modeli), diğer bir anlatımla, iki seviyeli doğrulayıcı faktör analizi modeli Şekil 2'de verilmiştir.

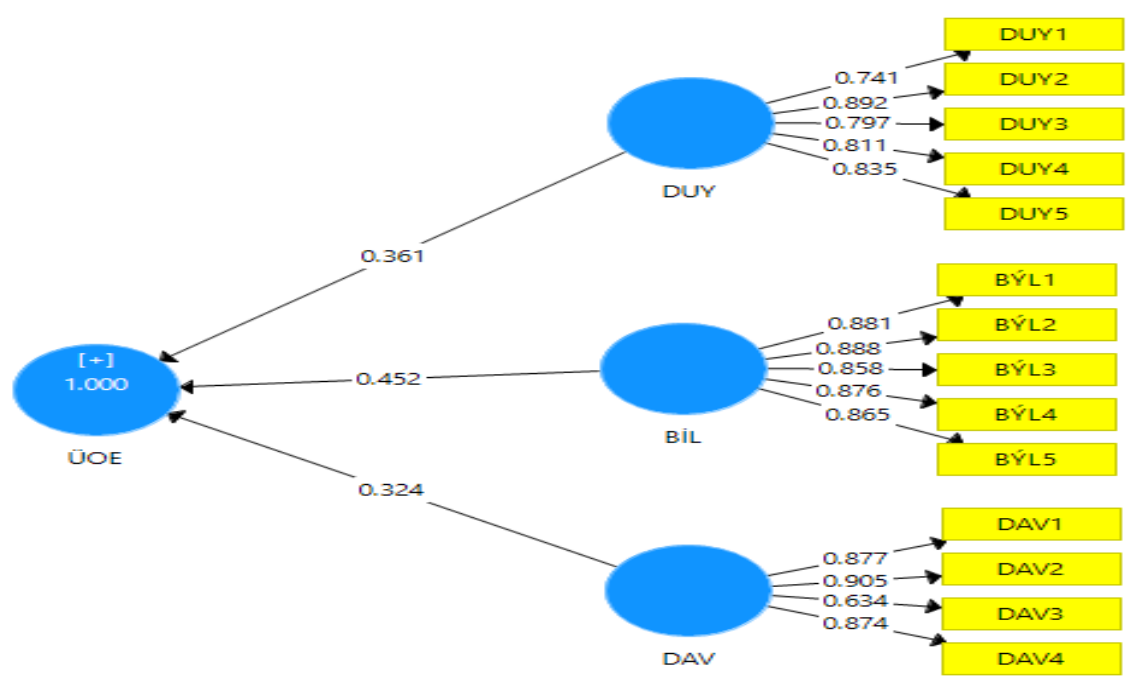

Şekil 2. SmartPLS Paket Programında Araştırma Modeli 
Şekil 2'deki modelde bir gizil değişken ve bu gizil değişkene bağlı üç adet ölçülebilir değişken bulunmaktadır ve 1'inci alt boyutunda beş adet, 2'nci alt boyutunda beş adet, 3'üncü alt boyutunda dört adet olmak üzere toplam on dört adet soru (ölçülebilen değişken) yer almaktadır.

Üretken Enerji Ölçeği ile ilgili olarak yapılması gereken ilk şey, faktör analizi sonuçlarına bakmaktır. SmartPLS paket programında faktör analizi ile ilgili modül çalıştırılırken parametre değerleri olarak maksimum iterasyon olarak " 500 " ve durdurma kriteri olarak " 3 " girildikten sonra modül çalıştırılmıştır. Bu değerler, SmartPLS paket programı için önerilen değerlerdir. Bu kapsamda, Üretken Enerji Ölçeği'ne ait elde edilen faktör yükleri (Outer loadings) Tablo 6'da verilmiştir. PLS-SEM yönteminde faktör yükleri ölçekteki ifadelerin faktör ile ne derece ilgili olduğunu gösterir ve SmartPLS paket programında elde edilen bu değerlerin \%70'in üzerinde olması tercih edilir (Hair vd., 2017).

Tablo 6. Üretken Enerji Ölçeği Açıklayııı Faktör Analizi

\begin{tabular}{c|cc|cc|cc}
\hline \multirow{2}{*}{$\begin{array}{c}\text { Ölçeğin Alt } \\
\text { Boyutları }\end{array}$} & \multicolumn{2}{|c|}{ Duygusal Alt Boyutu } & \multicolumn{2}{c|}{ Bilişsel Alt Boyutu } & \multicolumn{2}{c}{ Davranışsal Alt Boyutu } \\
\hline \multirow{2}{*}{$\begin{array}{c}\text { Ölçeğin } \\
\text { Maddeleri }\end{array}$} & Maddeler & Faktör Yükü & Maddeler & Faktör Yükü & Maddeler & Faktör Yükü \\
\cline { 2 - 6 } ve & DUY1 & 0.741 & BİL1 & 0.881 & DAV1 & 0.877 \\
Faktör & DUY2 & 0.892 & BİL2 & 0.888 & DAV2 & 0.905 \\
Yükleri & DUY3 & 0.797 & BİL3 & 0.858 & DAV3 & 0.634 \\
& DUY4 & 0.811 & BİL4 & 0.876 & DAV4 & 0.874 \\
\hline
\end{tabular}

Tablo 6'da yer alan Üretken Enerji Ölçeği'nin alt boyutlarına ait faktör yükleri incelendiğinde; bütün faktör yüklerinin yazında yer alan referans değerinin (\%70) üzerinde olduğu görülmektedir. Dolayısıyla ölçeğin yapısında ve madde sayısında herhangi bir değişiklik yapılmadan kullanılmasının uygun olduğuna karar verilmiştir.

SmartPLS paket programında kurulan modelin geçerliği ve güvenirliği ile ilgili olarak; faktör yüklerine bakılmasının dışında iç tutarlılık katsayısı (Cronbach Alfa Katsayısı) ve yakınsama geçerliği (Veri Tutarlılık (Rho_A) Katsayısı, Birleşik Güvenirlik (Composite Reliability) Katsayısı ve Çıkarılan Ortak Varyans (AVE (Average Variance Extracted)) değerlerine ve ayrışma geçerliği (Fornell-Larcker Kriterleri ve Heterotrait-Monotrait Oranı) değerlerine de bakılmaktadır. İç tutarlılık katsayısı, ölçüm modelinin içsel tutarlılı̆̆ını gösterir ve katsayının \%50'nin üzerinde olması durumunda "ölçeğin içsel tutarlılı̆̆ı yeterli seviyededir" şeklinde; Veri Tutarlılık Katsayısı, ölçüm modelinin veri tutarlılığını gösterir ve katsayının \%70'in üzerinde olması durumunda "faktör öğeleri güvenilirdir" şeklinde; Birleşik Güvenirlik Katsayısı, ölçüm modelinin bir bütün olarak güvenirliğini gösterir ve katsayının \%70'in üzerinde olması surumunda "modelin bütünlüğü güvenilirdir" şeklinde; Çıkarılan Ortak Varyans, ölçüm modelinin uyuşum geçerliğini gösterir ve katsayının \%50'nin üzerinde olması durumunda "kurulan model, uyuşum geçerliğine sahiptir" şeklinde yorumlanır (Fornell ve Larcker, 1981; Hair, William, Barry ve Rolph, 2006; Hair, Tomas, Christian ve Marko, 2014). Bu kapsamda kurulan modelle ilgili hesaplanan geçerlik ve güvenirlik sonuçları Tablo 7'de verilmiştir.

Tablo 7. Ölçeğin Güvenirlik Katsayıları

\begin{tabular}{ccccc}
\hline Ölçekler & $\begin{array}{c}\text { İç Tutarlılık } \\
\text { Katsayısı }\end{array}$ & $\begin{array}{c}\text { Veri Tutarlılık } \\
\text { Katsayısı }\end{array}$ & $\begin{array}{c}\text { Birleşik } \\
\text { Güvenirlik } \\
\text { Katsayıs }\end{array}$ & $\begin{array}{c}\text { Çıkarılan Ortak } \\
\text { Varyans }\end{array}$ \\
\hline BíL & 0.923 & 0.924 & 0.942 & 0.763 \\
DAV & 0.844 & 0.875 & 0.897 & 0.689 \\
DUY & 0.874 & 0.876 & 0.909 & 0.667 \\
UOE & 0.934 & 0.939 & 0.943 & 0.545 \\
\hline
\end{tabular}

Tablo 7'de yer alan güvenirlik değerleri incelendiğinde; söz konusu değerlerin, Nunnally (1978) ve Fornell ve Larcker (1981) tarafından belirlenen eşik seviyelerinin üzerinde olduğu görülmektedir. Bu veriler, ölçeğin geçerli ve güvenilir olduğunu göstermektedir. 
Yapılan çalışmada ayrışma geçerliğinin tespitinde, Fornell ve Larcker (1981) ile Henseler, Christian ve Marko (2015) tarafından önerilen Fornell-Larcker kriterleri ile Heterotrait-Monotrait oranı kullanılmıştır. FornellLarcker kriterlerine göre, Çıkarılan Ortak Varyans değerlerinin karekökü, araştırmada yer alan yapılar arasındaki korelasyonlardan yüksek olmalıdır. Diğer bir anlatımla, Fornell ve Larcker (1981) kriterine göre, ölçüm modelinde kullanılan her bir gizil değişkenin AVE değerlerinin karekökünün, bulundukları sütunlardaki korelasyon değerlerinden daha büyük olması gerekmektedir. Heterotrait-Monotrait oranı ise araştırmada yer alan tüm değişkenlere ait ifadelerin korelasyonlarının ortalamasının ayn değişkene ait ifadelerin korelasyonlarının geometrik ortalamalara oranlarıdır ve bu oranın 0.85 veya $0.90^{\prime}$ dan küçük olması tercih edilir. Bu kapsamda kurulan modelin ayrışma geçerliği ile ilgili hesaplanan değerler Tablo 8'de verilmiştir.

Tablo 8. Ölçeğin Alt Boyutlarının Ayrışma Geçerliği Katsayıları

\begin{tabular}{cccc|cccc}
\hline \multicolumn{3}{c|}{ Fornell-Larcker Kriterleri } & \multicolumn{3}{c}{ Heterotrait-Monotrait Oranı } \\
\hline $\begin{array}{c}\text { Ölçeğin Alt } \\
\text { Boyutları }\end{array}$ & BİL & DAV & DUY & $\begin{array}{c}\text { Ölçeğin Alt } \\
\text { Boyutları }\end{array}$ & BİL & DAV & DUY \\
\hline BİL & $0.874^{*}$ & & & BİL & & & \\
DAV & $0.759^{* *}$ & $0.830^{*}$ & & DAV & 0.843 & & \\
DUY & $0.607^{* *}$ & $0.593^{* *}$ & $0.817^{*}$ & DUY & 0.674 & 0.685 & \\
\hline
\end{tabular}

${ }^{*}$ Hesaplanan değerler Çıkarılan Ortak Varyans değerlerinin kareköküdür.

** Hesaplanan değerler gizil değişkenler arasındaki korelasyon katsayılarıdır.

Tablo 8'de yer alan ayrışma geçerliği kapsamında Fornell-Larcker kriterleri ve Heterotrait-Monotrait oranı ile ilgili değerler incelendiğinde; değerlerin yazında yer alan referans değerleri ile uyumlu olduğu görülmüş, modelin ayrışma geçerliğine sahip olduğu sonucuna ulaşılmıştır. Ayrıca ayrışma geçerliğinin incelendiği Tablo 8' de yer alan Fornell-Larcker Kriterleri çizelgesinde değişkenler arasındaki korelasyon değerleri de yer almaktadır. Söz konusu korelasyon değerleri Evans (1996)'in makalesinde yer alan referans korelasyon değerlerine ("0,00-0,19:Çok zayıf, 0,20-0,39:Zayıf, 0,40-0,59:Orta, 0,60-0,79:Güçlü ve 0,80-1,00:Çok güçlü") göre yorumlandığında; BìL ile DUY arasında anlamlı, aynı yönlü ve güçlü düzeyde bir ilişki $(r=0.607, p<0.05)$, DAV ile DUY arasında anlamlı, aynı yönlü ve orta düzeyde bir ilişki $(r=0.593, p<0.05)$ ve DAV ile BíL arasında anlamlı, aynı yönlü ve güçlü düzeyde bir ilişki $(r=0.759, p<0.05)$ olduğu tespit edilmiştir. Bu şekilde hesaplanan korelasyon katsayıları da ölçeğin alt boyutları arasında uygun seviyede bir ilişkinin olduğunu teyit etmektedir.

Üretken Enerji Ölçeği'nin geçerliği kapsamında, uyum iyiliği değerlerine bakılması gerekmektedir. Uyum iyiliği değerleri olarak SmartPLS paket programında genellikle iki adet uyum iyiliği değeri kullanılmaktadır. Bu uyum iyiliği değerleri SRMR (Standardized Root Mean Square Residual) ve NFI (Normed Fit Index) değerleridir (Hair, Hult, Ringle ve Sarstedt, 2017). Bu kapsamda Üretken Enerji Ölçeği'nin hesaplanan uyum iyiliği değerleri olarak $S R M R$ değeri 0.032 ve NFI değeri ise 0.985 olarak hesap edilmiştir. Üretken Enerji Ölçeği'nin $S R M R$ ve NFI uyum iyiliği değerleri incelendiğinde; söz konusu uyum iyiliği değerlerinin referans değerlerine $(S R M R<0.08$ ve NFI>0.90) uygun olduğu ve Üretken Enerji Ölçeği'nin iyi uyumlu bir ölçek olduğu sonucuna ulaşılmıştır.

\section{SONUÇ VE TARTIŞMA}

Bu çalışmada, Cole, Bruch ve Vogel (2012) tarafından geliştirilen günümüzde de kullanılabileceği değerlendirilen Üretken Enerji Ölçeği'nin Türkçe uyarlaması ile geçerlik ve güvenirlik çalışması yapılmış, sonuçta bu ölçeğin Türkçe yazına kazandırılması amaçlanmıştır. Ölçek, ilk olarak Brislin (1970) tarafından önerilen metodolojiye uygun olarak Türkçe'ye tercüme edilmiş, ölçek maddeleri uzman görüşünden yararlanarak değerlendirilmiştir. Yapılan değerlendirme neticesinde; ölçeğin orijinal halinde olduğu gibi üç alt boyutlu olmasının ve alt boyutları temsilen, toplamda 14 adet sorudan herhangi birinin çıkartılmadan Türkçe yazında kullanılabileceği değerlendirilmiştir. Müteakiben, ölçeğin geçerlik ve güvenirlik çalışması yapılmıştır. Yapılan analizler neticesinde; ölçeğin geçerli ve güvenilir olduğu, ulusal yazında sosyal bilimler alanında yapılacak araştırmalarda kullanılabileceği tespit edilmiştir. Bu kapsamda; ölçekle ilgili SmartPLS paket programında yapılan faktör analizi sonucunda ölçeğin üç boyutlu olduğu ve faktör yüklerinin 0.861- 
0.915 arasında (1'inci alt boyut faktör yükleri: 0.741-0.892 arasında, 2'nci alt boyut faktör yükleri: 0.858-0.888 arasında ve 3'ncü alt faktör yükleri: 0.634-0.905 arasında) değerler aldığı, ölçeğin bütünü için Cronbach alfa katsayısı, 0.934 (1'nci alt boyutu için 0.923, 2'nci alt boyutu için 0.923, 3'üncü alt boyutu için 0.844), birleşme geçerliği katsayıları, 0.897-0.943 arasında, ayrışma geçerliği (AVE) katsayıları, 0.545-0.763 arasında ve uyum iyiliği değerleri, $S R M R=0.032$ ve NFI=0.985 olarak hesaplanmıştır. Elde edilen bulgular ölçeğin Türkçe versiyonunun, Cole, Bruch ve Vogel (2012), Grobler ve Grobler (2019) ve Alexiou, Khanagha ve Schippers (2019) tarafından elde edilen geçerlik ve güvenirlik sonuçlarıyla uyumlu olduğunu göstermektedir. Ayrıca bu değerlerin anlamlılık sınaması ise tekrar örnekleme yoluyla hesap edilmiş, tamamının anlamlı olduğu görülmüştür $(p<0.05)$.

Sonuç olarak; hesap edilen bütün faktör yüklerinin, birleşme ve ayrışma geçerlik değerlerinin, Cronbach alfa katsayı ve uyum iyiliği değerlerinin yazında belirtilen referans değerlerinde olduğu ve ölçeğin Türkiye'de sosyal bilimler alanında yapılacak çalı̧̧malarda kullanılabileceği, ancak kullanılmadan önce doğrulayıcı faktör analizi yapılmasının gerekli olduğu söylenebilir.

Bu çalışmanın bazı kısıtları da bulunmaktadır. Bu kapsamda; araştırmanın döküm sanayisi sektöründe çalışan bir firma üzerinde yapılmış olması bu araştırmanın en önemli kısıtıdır. Bu ölçeğin çalışma hayatında kullanılabileceği öngörülmüş olmakla birlikte, diğer sektörlerde de kullanılarak sonuçlarının değerlendirilmesi gerekir. Ayrıca daha büyük bir veri seti kullanılarak ölçeğin parametrik yöntemler ile geçerliğinin ve güvenirliğinin kontrolü ile ayrı bir çalışma yapılabilir.

\section{Kaynakça}

Alexiou, A. Khanagha, S. ve Schippers, M.C. (2019). Productive organizational energy mediates the impact of organizational structure on absorptive capacity. Long Range Planning, 52(2), 155-172.

Alpar, R. (2012). Uygulamalı İstatistik ve Geçerlik-Güvenirlik. Detay, Ankara.

Atwater, L. ve Carmeli, A. (2009). Leader-member exchange, feelings of energy, and involvement in creative work. The Leadership Quarterly, 20, 264-275.

Baker, W.E. (2019). Emotional energy, relational energy, and organizational energy: Toward a multilevel model. Annual Review of Organizational Psychology and Organizational Behavior, 6, 373-95.

Bayram, N. (2016). Yapısal Eşitlik Modellemesine Giriş AMOS Uygulamaları. 3.b., Ezgi, Bursa.

Brislin, R. (1970). Back-translation for cross-cultural research. Journal of Cross-Cultural Psychology, 1, 185-216.

Bruch, H. ve Kunz, J.J. (2013). Organisational energy as the engine of success: Managing energy effectively with strategic HR development. In: (Matthias T. Meifert Eds.) Strategic Human Resource Development, Berlin: Springer, 329-338.

Bruch, H. ve Vogel, B. (2011). Fully charged: How great leaders boost their organization's energy and ignite high performance. Cambridge, MA: Harvard Business School Press.

Bruch, H., Walter, F. ve Voelpel, S. (2006). Charismatic leadership and collective mental energy: The mediating role of emotional energy and job involvement climate. Critical Management Studies Research Workshop, Atlanta.

Bruch, H. ve Ghoshal, S. (2003). Unleashing organizational energy. MIT Swan Management Review, Fall, 45-52.

Burns, T. ve Stalker, G. M. (2011). Mechanistic and organic systems of management. In: (Mary Godwyn ve Jody Hoffer Gittell Eds.) Sociology of Organizations: Structures and Relationships, SAGE Publications, 14-18.

Cole, M.S., Bruch, H. ve Vogel, B. (2012). Energy at work: A measurement validation and linkage to unit effectiveness. Journal of Organizational Behavior, 33, 445-467. 
M. Bekmezci - K. Orçanlı - H. Boztoprak 12/3 (2020) 2655-2668

Cole, M.S., Bruch, H. ve Vogel, B. (2005). Development and validation of a measure of organizational energy. Proceedings of the Sixty-fourth Annual Meeting of the Academy of Management, https://journals.aom.org/doi/pdf/10.5465/ambpp.2005.18781081c Erişim Tarihi: 16.06.2020 14:07.

Compeau, D. ve Higgins, C. (1995). Computer self-efficacy: Development of a measure and initial test. MIS Quarterly, 19(2), 189-211

Cross, R., Baker, W. ve Parker, A. (2003). What creates energy in organizations? MIT Swan Management Review, Summer, 51-53.

Dhawan, S.K., Roy, S. ve Kumar, S. (2002). Organizational energy: An empirical study in Indian R\&D laboratories. RED Management, 32(5), 397-408.

Eisenhardt, K.M, Furr, N.R. ve Bingham, C.B. (2010). Micro foundations of performance: Balancing efficiency and flexibility in dynamic environments. Organization Science, 21(6), 1263-1273.

Eisenhardt, K.M. ve Martin, J.A. (2000). Dynamic capabilities: What are they? Strategic Management Journal, $21,1105-1121$.

Evans, J. D. (1996), Straightforward Statistics for the behavioral sciences. Pacific Grove, CA: Brooks/Cole Publishing, USA.

Fornell, C. ve Larcker, D.F. (1981). Evaluating structural equation models with unobservable variables and measurement error. Journal of Marketing Research, 18, 39-50.

Grobler, S. ve Grobler, A. (2019). Ethical leadership, person-organizational fit, and productive energy: A South African sectoral comparative study. Ethics $\mathcal{E}$ Behavior, https://doi.org/10.1080/10508422.2019.1699412.

Hair, J.F., Black, W.C., Babin, B.J. ve Anderson, R.E. (2006). Multivariate data analysis. Upper Saddle River, NJ: Pearson Prentice Hall.

Henseler, Jörg, Christian M. Ringle ve Marko Sarstedt (2015). A new criterion for assessing discirimant validity in variance-based structural equation modeling. Journal of the Academy of Marketing Science, 43, 115-135.

Kunze, F. ve Bruch, H. (2010). Age-based faultlines and perceived productive energy: The moderation of transformational leadership. Small Group Research, 41(5), 593-620.

Miner, J.B. (1980). Limited domain theories of organizational energy. (Craig C. Pinder ve Larry F. Moor Eds.) Middle Range Theory and the Study of Organizations, Martinus Nijhoff, Boston: 273-286.

Nunnaly, J. (1978). Psychometric theory. New York: McGraw-Hill.

Schiuma, G., Mason, S. ve Kennerly, M. (2007). Assessing energies within organizations. Measuring Business Excellence, 11(3), 69-78.

Seibert, S.E., Silver, S.R. ve Randolph, W.A. (2016). Taking empowerment to the next level: A multiple-level model of empowerment, performance, and satisfaction. Acad. Manag. J. 47(3), 332-349.

Shirom, A. (2003). Feeling vigorous at work? The construct of vigor and the study of positive affects in organizations. In: (D. Ganster \& P. L. Perrewe Eds.) Research in organizational stress and wellbeing, Greenwich, CT: JAI Press, 135-165.

Singh, B. ve Rao, M.K. (2016). Effect of intellectual capital on dynamic capabilities. Journal of Organizational Change Management, 29(2): 129-149.

Tosey, P. ve Smith, P.A.C. (1999). Assessing the learning organization: Part 2 - Exploring practical assessment approaches. The Learning Organization, 6(3), 107-115. 
EK:

\section{Ölçeğin İngilizcesi ve Türkçesi}

\section{Productive Energy Measure}

\section{Affective dimension}

1.1. People in my work group feel excited in their job.

1.2. People in my work group feel enthusiastic in their job.

1.3. People in my work group feel energetic in their job.

1.4. People in my work group feel inspired in their job.

1.5. People in my work group feel ecstatic in their job.

\section{Cognitive dimension}

2.1. My work group is ready to act at any given time.

2.2. People in my work group are mentally alert.

2.3. In my work group, there is a collective desire to make something happen.

2.4. People in my work group really care about the fate of this company.

2.5. People in my work group are always on the lookout for new opportunities.

\section{Behavioral dimension}

3.1. People in my work group go out of their way to ensure the company succeeds.

3.2. People in my work group often work extremely long hours without complaining.

3.3. There has been a great deal of activity in my work group.

3.4. People in my work group are working at a very fast pace.

Responses: Responses to the affect (five) items were on a five-point frequency scale ( $1=$ never; $5=$ frequently, if not always). Responses to the cognition (five) items and behavioral (four) items were on a five-point agreement continuum ( 1 = strongly disagree; 5 = strongly agree $)$.

\section{Üretken Enerji Ölçeği}

\section{Duygusal Boyut}

1.1. Çalışma grubumdaki kişiler yaptıkları işten heyecan duyar.

1.2. Çalışma grubumdaki kişiler işlerini coşkuyla yapar.

1.3. Çalışma grubumdaki kişiler işlerinde kendilerini enerjik hisseder.

1.4. Çalışma grubumdaki kişiler işlerinde kendilerini çok iyi hisseder.

1.5. Çalışma grubumdaki kişiler işlerinde kendilerini mutlu hisseder.

Yanıtlar: (1) Kesinlikle hayır; (2) Ara sıra; (3) Bazen; (4) Sık sık (5) Kesinlikle evet

\section{Bilişsel Boyut}

2.1. Çalışma grubumdaki kişiler her an harekete geçmeye hazırdır.

2.2. Çalışma grubumdaki kişiler zihinsel olarak hazırdır.

2.3. Çalışma grubumda, bir şeylerin gerçekleşmesi için ortak bir arzu vardır. 
M. Bekmezci - K. Orçanlı - H. Boztoprak 12/3 (2020) 2655-2668

2.4. Çalışma grubumdaki kişiler çalıştığımız kurumun kaderini gerçekten önemser.

2.5. Çalışma grubumdaki kişiler işlerini yapma konusunda her zaman yeni firsatlar kollar.

Yanıtlar: (1) Kesinlikle katılmıyorum; (2) Katılmıyorum; (3) Kararsızım; (4) Katılıyorum; (5) Kesinlikle katılıyorum.

\section{Davranışsal Boyut}

3.1. Çalışma grubumdaki kişiler çalıştığımız kurumun başarılı olması için fazladan çaba sarf eder.

3.2. Çalışma grubumdaki kişiler çoğu zaman şikâyet etmeksizin uzun saatler çalışır.

3.3. Çalışma grubumda çok fazla faaliyet gerçekleştirilir.

3.4. Çalışma grubumdaki kişiler çok hızlı bir tempoda çalışır.

Yanttlar: (1) Kesinlikle katılmıyorum; (2) Katılmıyorum; (3) Kararsızım; (4) Katılıyorum; (5) Kesinlikle katılıyorum. 